Résumés des conférences et travaux

\title{
François Martin (1948-2015)
}

\section{Alain Thote}

\section{OpenEdition \\ Journals}

Édition électronique

URL : https://journals.openedition.org/ashp/1789

DOI : $10.4000 /$ ashp. 1789

ISSN : 1969-6310

Éditeur

Publications de l'École Pratique des Hautes Études

Édition imprimée

Date de publication : 1 septembre 2016

Pagination : ix-xi

ISSN : 0766-0677

Référence électronique

Alain Thote, "François Martin (1948-2015) », Annuaire de l'École pratique des hautes études (EPHE), Section des sciences historiques et philologiques [En ligne], 147 | 2016, mis en ligne le 08 septembre 2016, consulté le 06 juillet 2021. URL : http://journals.openedition.org/ashp/1789 ; DOI : https:// doi.org/10.4000/ashp.1789 


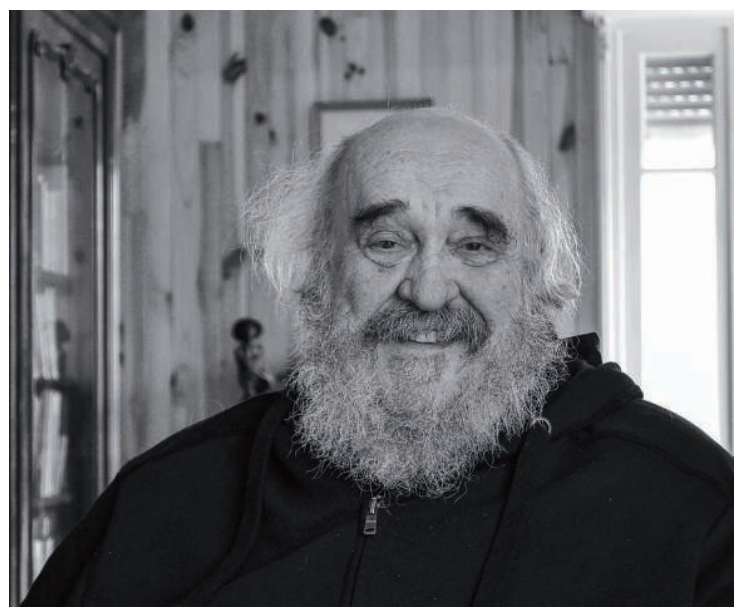

FRANÇOIS MARTIN (1948-2015) çois Martin à la chaire d'histoire et de philologie de la Chine classique. C'était sans imaginer que la mort allait saisir brutalement notre collègue au moment de prendre sa retraite, moins de quatre mois plus tard, le 16 septembre. Mais lui qui avait subi plusieurs maladies depuis le début des années 2000 et voyait sa santé décliner, avait probablement le pressentiment de sa fin prochaine. C'est du moins ce que laissent entendre quelques paroles adressées à ses proches au cours des derniers mois, mais dites avec ce ton léger qu'il prenait toujours lorsqu'il évoquait ses ennuis de santé, même les plus graves.

François Martin est né en 1948, il aurait eu soixante-sept ans en décembre dernier. Sa jeunesse s'est partagée entre le Mans où résidaient ses parents et la maison familiale de Saint-Quay-Portrieux en Bretagne où il garda toute sa vie son port d'attache. Une enfance heureuse bercée dans l'espoir que nourrissaient ses parents de le voir un jour banquier ou notaire fut pourtant marquée dès l'adolescence par l'appel du large, et plus précisément de l'Asie. N'avait-il pas à l'âge de quinze ans entrepris un grand plan, minutieusement dessiné, d'Angkor Vat? Il était alors incollable sur l'histoire cambodgienne. Du côté de sa mère, un oncle voyageur ayant bourlingué en Algérie, au Vietnam, au Cambodge pour finalement se retirer et mourir à Tahiti lui rapportait de ses pérégrinations des cadeaux qui ne manquaient pas de le séduire. En 1966 il entre à l'Institut national des langues orientales pour y apprendre le japonais, mais c'est en chinois qu'on l'inscrit, et donc il fait du chinois. En deuxième année, il commence le japonais, tout en s'initiant au coréen, au mongol, et à diverses langues qui toutes attirent le jeune homme qu'il était alors, saisi d'un appétit boulimique de 
connaissances nouvelles. Avant de passer son bac, il avait pris des cours de breton par correspondance, cet enseignement n'étant pas encore proposé dans les établissements scolaires, et il s'était aussi investi seul dans l'apprentissage du sanscrit. À l'été 1967, un stage au Crédit Lyonnais devait en revanche le décourager définitivement de s'intéresser à la finance, au désespoir de ses parents.

Avec une licence de japonais et une maîtrise de chinois, François Martin obtient en 1970 une bourse du ministère des Affaires étrangères du Japon qui lui permet d'étudier dans la très renommée université Tôdai à Tôkyô. Il y apprend le chinois classique, se fortifie en japonais, et se nourrit de la culture extrême-orientale, faisant aussi de brefs séjours en Corée. Lorsqu'il rentre en France, plusieurs voies se présentent à lui : il passe le concours du Quai d'Orsay, mais il y échoue de peu, fort heureusement pour nous. On lui propose alors d'être lecteur de japonais à l'université Paris-VII et de donner quelques cours de chinois. Étudiants à Paris-VII, nous étions une trentaine à suivre ses cours, parmi lesquels Toshiko, qui devint son épouse en 1981. C'étaient les débuts d'un enseignement qui allait sans cesse s'enrichir au fil des ans. À peine plus âgé que ses étudiants, il était un maître à nos yeux, tant il savait captiver son auditoire. Son cours portait sur la grammaire du chinois, mais déjà il nourrissait son enseignement de digressions sur la culture chinoise pour laquelle il semblait ne pas avoir de secrets. Nous étions surpris par ce qu'il nous apprenait, et pleinement séduits aussi. La plupart d'entre nous étions en effet venus au chinois par la Révolution culturelle, et le décalage était grand entre son enseignement et les bondieuseries maoïstes que déversaient les lecteurs envoyés par l'ambassade de Chine.

Mais, plus important, François Martin prépare alors une thèse de troisième cycle à Paris-VII sous la direction de Jean-Pierre Diény, directeur d'études à l'EPHE, son maître. Soutenue brillamment en 1979, cette thèse sur Le Yutai xinyong et la nouvelle poésie galante en Chine au VI siècle va lui ouvrir les portes de l'université. Il est nommé maître de conférences à Paris-VII. Cependant, tout en aimant enseigner, il aspirait à faire de la recherche, et avait toutes les compétences pour suivre cette voie. La chance voulut qu'il bénéficiât d'une disponibilité pour un séjour de deux ans à l'université de Genève. C'était en 1989-1990. Il y serait certainement resté si JeanPierre Diény ne l'avait incité à se présenter à l'EPHE pour y prendre sa succession. François Martin était bien l'héritier spirituel de Jean-Pierre Diény, tant par l'esprit de ses recherches que par les périodes couvertes, entre la haute Antiquité et le Moyen Âge chinois, que l'on situe aux $\mathrm{III}^{\mathrm{e}}-\mathrm{IX}^{\mathrm{e}}$ siècles. Élu en 1992 à la chaire d'histoire et philologie de la Chine classique, il commence un enseignement sur la poésie. Nul mieux que lui ne connaissait la poésie chinoise, sur laquelle il a effectué la plus grande partie de ses recherches. Il excellait à la comprendre, à la traduire, mais également à la pratiquer. Il a ainsi participé en Corée à des joutes poétiques organisées sur le modèle de celles de la Chine classique. Au cours des années récentes, sans délaisser la poésie, il s'est progressivement tourné vers l'histoire des Six dynasties, une période mouvementée et complexe qui couvre les $\mathrm{III}^{\mathrm{e}}-\mathrm{VI}^{\mathrm{e}}$ siècles, avec l'intention d'écrire un livre pour Les Belles Lettres. Cet ouvrage, trop peu avancé, ne verra pas le jour, mais François Martin avait également entrepris un programme collectif de dictionnaire des grandes figures et des groupes sociaux de cette période. Pour mieux connaître les textes bouddhiques de l'époque concernée, il s'était pleinement investi dans une étude 
approfondie du sanscrit. Sous sa direction ont travaillé de nombreux chercheurs, dont certains de ses meilleurs disciples. Comme tout ce qu'il a entrepris et publié, ce dictionnaire promet d'être un excellent outil de recherche sur une période de l'histoire chinoise qui reste encore mal explorée.

De santé fragile, François Martin aimait trop la vie pour se laisser abattre par le sort. Il était un homme entreprenant. Ne s'était-il pas construit un pavillon chinois dans son jardin de Bretagne? N'avait-il pas au fil des ans constitué une collection d'objets d'art chinois réunis avec cette belle intuition qui était la sienne? Cet homme érudit, et curieux de nature, vivait intensément dans toutes les cultures avec lesquelles il se sentait en harmonie.

Il y a cinq ou six ans, il a repris le breton, s'est constitué une riche bibliothèque dans cette langue et sur cette langue. Il était conscient en effet que le breton serait amené à disparaître et qu'il fallait le sauver en le pratiquant chaque fois que possible. De sa belle voix, douce et ferme, servi par son physique de barde, il pouvait chanter en breton devant une assistance nombreuse, ce qui lui a valu les honneurs de la presse.

Dans les colloques, ses interventions, souvent improvisées ou qui paraissaient telles lors des discussions entre les participants, étaient toujours inspirées. Il aimait faire partager ses découvertes, ses enthousiasmes, et le faisait avec un tel naturel, avec une telle chaleur que la conversation prenait d'emblée un tour amical plein de connivences. Son érudition, la finesse de ses analyses, la délicatesse de ses propos en imposaient pourtant, plus que son physique majestueux. On était pris sous le charme d'une conversation, qui pouvait s'arrêter et être reprise à tout moment, comme si le fil ne s'en était jamais rompu.

Aujourd'hui, hélas, le fil s'est rompu, mais François Martin nous laisse une œuvre de très belle qualité, et si elle demeure inachevée, elle sera une source d'inspiration et à bien des égards un modèle pour les sinologues aujourd'hui et demain.

Alain Tноте 